\title{
Editorial
}

\section{Innovation: Requirements for New Agenda}

\author{
Carlos Américo Pacheco*
}

reitor@ita.br

Innovation is a trendy word in Brazil. In national life, rarely has there been a consensus on the need to trigger it. Leaders both from the private and the public sector have been working on this agenda. This diagnosis mostly relies on the need to increase the competitiveness in Brazil and on the fact that innovation is currently the main determinant of productivity.

Opinions converge on the fact that, in the long term, there will be many opportunities for growth. But there is also great concern that this growth should be focused on the internal market and on the exportation of commodities, leading to higher external deficit in comparison to the current numbers observed in technology intensive sectors. That is why the emphasis is on innovation, on technological development and on industrial policy.

But there is a huge difference between the consensus and actually changing reality. And despite the efforts that have been made probably for more than ten years to introduce the issue of innovation in the agenda of the State, there have been few advances.

Part of our difficulties is related to resources. When the reform of incentive instruments of the National Innovation System took place, more than ten years ago, with the creation of the Sectoral Funds, there were great expectations that these resources could put Brazil in a different level in terms of science, technology and innovation. These resources are significant and currently raise around $\mathrm{R} \$ 4.5$ billion a year. If there were not so many limits and dispersion, it would be possible to structure a reasonable scientific policy.

But these resources are not sufficient in order for Brazil to be able to build a reasonable technology policy that supports innovation. One example is valid to understand that this would require much higher efforts: industrial scale-up. Taking a solution to the market usually means to produce many prototypes, to perform trials, to improve each step of the product and its manufacturing. In the processing industry - which comprehends many of the sectors in which Brazil is more competitive -, the scale-up implies investments in demonstration and pilot plants. These expenses, in terms of greatness, are usually one or more times higher in relation to the early stages of research. In the aerospace and defense sector, taking a solution to the market has been possible in countries that are strongly positioned in the international scenario by means of governmental procurement. These orders pay for the nonrecurring costs of development and enable a minimum scale of production.

But besides resources, our difficulties to make progress in the constitution of what has been called an effective National Innovation System are also in the so called institutional aspects. The private-public interface - which is so emphasized in the world - is yet an obstacle for innovation in Brazil.

The Law of Innovation was an advance towards this direction. In concept, this law consisted of a private-public partnership with regards to the innovation system. It is interesting to notice that the Green Book of CT\&I dedicated one chapter to the so called institutional challenges. It starts with the statement: "One of the greatest challenges to incorporate Science, Technology and Innovation to the agenda of the Brazilian society is institutional". More emphasis on patents, creation of technology innovation teams, incentives to the cooperation between universities, institutes and companies etc., are part of what happened in Brazil after this debate.

\footnotetext{
*Graduated in Electronic Engineering by the Technological Institute of Aeronautics - ITA (1979), PhD in Economics at Univesidade Estadual de Campinas - UNICAMP (1996) and Postdoc at Columbia University (2005). Professor at UNICAMP, Advisor of the Board of Industrial Policies and Technology of the National Confederation of Industry - CNI and member of the Technology Council of the Federation of Industries of São Paulo - FIESP. Vice-minister of Science and Technology of Brazil (1999-2002) and Vice Secretary for Economic Development of São Paulo (2007). Member of the Board of Directors and Guidance of the following organizations: Management and Strategic Studies Center CGEE, National Institute for Space Research - INPE, Instituto Institute of Technological Research of São Paulo - IPT, Financier of Studies and Projects - FINEP, among others. Dr. Pacheco has experience in industrial and technological economics and also in scientific, technological and innovation policies. He is currently the Rector of ITA.
} 
But it is also worth to mention that ten years after the CT\&I Conference, which brought the discussion about the first version of that Law, the environment of cooperation between public and private entities is still stopped. Mostly because of the organizational models and rules that limit public research institutions.

Once again, the example of the aerospace sector is emblematic. One of the most creative institutional solutions that Brazil has heard of when it comes to teaching and applied research activities was conceived here. The creation of the Aerospace Technical Center more than sixty years ago was not only brave, but absolutely innovative.

Today, this agenda is back. The initiative of the National Congress to discuss a new National Code of CT\&I, which would be an updated version of the Innovation Law, brings this opportunity. It is a complex, gigantic and hard task. But this will be, without a doubt, one of our challenges for the next few years.

The enlargement of the Technological Institute of Aeronautics (ITA) and the opportunities that it brings to the revitalization of the Department of Science and Aerospace Technology (DCTA) compose a very appropriate moment to rethink our organizations, their models and difficulties, which clearly prevent us from doing what society expects from us. Changing this reality is something we should do, and, undoubtedly, we will. 